\title{
Effect of Advancing Direction of Working Face on Mining Stress Distribution in Deep Coal Mine
}

\author{
Yuesong Tang $\mathbb{D},{ }^{1,2}$ Wenchao Sun $\mathbb{D}^{1},{ }^{1}$ Xin Zhang $\mathbb{D}^{1,2}$ and Pengju Liu $\mathbb{D}^{1}$ \\ ${ }^{1}$ School of Energy and Mining Engineering, China University of Mining Technology-Beijing, Beijing 100083, China \\ ${ }^{2}$ Coal Industry Engineering Research Center of Top-Coal Caving Mining, Beijing 100083, China \\ Correspondence should be addressed to Yuesong Tang; tang_yuesong@163.com
}

Received 10 June 2021; Accepted 10 August 2021; Published 18 August 2021

Academic Editor: Gaofeng Song

Copyright ( 92021 Yuesong Tang et al. This is an open access article distributed under the Creative Commons Attribution License, which permits unrestricted use, distribution, and reproduction in any medium, provided the original work is properly cited.

Deep mining has become the normal state of coal mining; compared with the mine with shallow buried depth, the consequent high level of in situ stress and complex distribution have brought severe threats to the stability of the stope and the surrounding rock of the roadway. In this research, taking the 121304 working face of Kouzidong Mine as the engineering background, the characteristics of mining-induced stress distribution under complex in situ stress environment in deep mining are analyzed by using on-site measurement of the original rock stress and mining stress, establishing a theoretical model centered on the middle section of the working face, and establishing large-scale numerical calculation models for different advancing directions. It was found that under deep mining conditions, the maximum stress of the original rock is $25.12 \mathrm{MPa}$, and the direction is vertical. The advanced influence range of mining stress is about $150 \mathrm{~m}$, and the abutment pressure presents a three-peak distribution characteristic in front of the working face. The research results provide important theoretical guiding value for guiding the mining of coal mines with similar geological conditions.

\section{Introduction}

As the level of modern industry increases year by year, the eastern part of China needs more energy supplies [1-6]. The shallow resource was exhausted, and the deep ones begin to develop. As a result, the level of ground stress has risen and the distribution law has become more complicated [7-11]. The stability maintenance of surrounding rock during mining and roadway excavation is more complicated [12-16]. The critical factor which causes the fracture of the rock strata of the stope and roadway is in situ stress [17-20].

Radwan et al. [21] have determined the ground stress field, pore pressure, stress regime, and fracture gradient through on-site measurement of ground stress. It is discovered that the stress field rotates affected by geologic structure and the influence of the stress field rotation on the effect of resource extraction, thereby providing a reliable guarantee for the efficient exploitation of resources. Saeidi et al. [22] analyzed the in situ stress distribution characteristics of Niobec Mine, Quebec (Canada) and the influence of in situ stress uncertainty on stability evaluation of openpit slope. Whether a mining plan can be exploited successfully to a deeper mining level depends largely on whether the magnitude and direction of the in situ stress state can be fully considered. Many mines use in situ stress to evaluate the stability of structure of underground and, at the same time, the interpretation of various aspects of mine data and engineering judgments are generally based on mine depth functions and methods which are determined by the value of ground stress obtained from the results of stress measure. Guo et al. [23] statistically analyzed the distribution features and rules of ground stress in Chinese mines according to a massive data of measured results of ground stress and summarized the relationship between stress field type, stress magnitude, stress value, and buried depth. In order to study the splitting failure of high sidewall cavern under high in situ stress, Zhang et al. [24] carried out true three-dimensional (3D) geomechanical model test. In Zhang's paper, the main powerhouse of Pubudou Hydropower Station is taken as an example. By using self-developed 3D loading system and 
analogue materials, Zhang reproduced the splitting failure of high sidewall cavern under high ground stress. The formation factor and collapse feature of the split failure of the high side rock cavern have been revealed in this model test. Furthermore, it summarized credible evidence for further researches on the formation mechanism of the split failure of the high sidewall cavern under the action of high ground stress. Yang et al. [25] put forward stress initialization methods. According to the results from simulations, the stress initialization results obtained by implicit-explicit sequence method and dynain file method had a close relationship to the material model of rock. Compared with other methods, the explicit DR method has an obvious advantage in solution time. According to the on-site measurement of a deep mine, Qin et al. [26] have found that the immediate cause of the roadway deformation is the ground stress. A kind of support form of high strength prestressed bolt and cable anchor is proposed, and the best prestress ratio of the bolt and cable anchor was proposed according to the corresponding geological conditions. Li et al. [27] proposed an intelligent monitoring and dynamic control method for coal gangue image recognition to provide the optimal illumination environment for coal gangue recognition.

In summary, the magnitude and direction of in situ stress play an important role in the control of surrounding rock. Especially in deep mines, in situ stress has a greater impact on mining work [28-33]. When the working face is in the condition of large buried depth, due to the influence of high ground stress, the mine pressure behavior will be more severe under the mining disturbance, and the creep deformation of the roadway will occur for a long time after the support [34-36]. The increase of working face length will lead to the increase of stress concentration factor at both ends of the working face, and the increase of the length will slow down the advancing speed, which makes it difficult to support the stope and roadway at the end of the working face and cause serious coal wall spalling. This paper analyzes the influence of the angle between the advancing direction and the initial minimum principal stress on the mining stress field. A better understanding of the influence of the angle on the mining stress field mentioned above can better strengthen the roadway in a targeted way and achieve safe and efficient production. The law of influence on the mining stress field is of great significance for guiding the study of the stability of the surrounding rock in deep mines.

\section{Engineering Geological Background}

The 121304 working face of Kouzidong Mine, AnHui, is taken as the engineering background. Due to the large buried depth of the working face, and the length of the working face is more than $350 \mathrm{~m}$, it is a typical working face with complex ground stress and significant mine pressure. Rib spalling, roadway severe deformation, and floor heave are serious, as shown in Figure 1.

13-1 coal has been being mined at the working face, in which thickness is $5.2 \mathrm{~m}$, and the comprehensive geological column chart is shown in Figure 2. The coal seam was mined by the process of mining all heights at one time. The on-site stress measurement of the working face found that the maximum principal stress is the vertical stress with a magnitude of $25.12 \mathrm{MPa}$. The intermediate principal stress is a horizontal stress with a magnitude of $21.84 \mathrm{MPa}$, and the direction is $35^{\circ}$ west by north, and the minimum principal stress is the horizontal stress with a magnitude of $12.89 \mathrm{MPa}$, in which direction is perpendicular to the intermediate principal stress.

\section{Distribution Characteristics of Coal Abutment Pressure}

A simplified mechanical model of the working face section is established to analyze the distribution of abutment pressure in the coal seam area. As shown in Figure 3, the working face is regarded as a roadway with a circular cross section, surrounded by an equal-pressure homogeneous surrounding rock environment. According to the content and assumption of elastic mechanics, this is regarded as the stress distribution around the hole. In order to simplify the calculation, the weight of the surrounding rock within the range of $3-5 r_{0}$ around the hole (working face) can be ignored in the calculation process. $4 r_{0}$ is used in this paper.

Assuming the radius of the working face section is $r_{0}$, the polar coordinate system is established with the center of the section as the polar coordinate origin. The coordinates of any point outside the working face are $(r, \theta)$; by analysing the stress and strain of the point, the equilibrium differential equation of the point is listed as the following equation:

$$
\begin{gathered}
\left(\sigma_{r}+\frac{\partial \sigma_{r}}{\partial r} \mathrm{~d} r\right)(r+\mathrm{d} r) \mathrm{d} \theta-\sigma_{r} r \mathrm{~d} \theta-\left(\sigma_{r}+\frac{\partial \sigma_{t}}{\partial \theta} \mathrm{d} \theta\right) \mathrm{d} r \sin \frac{\mathrm{d} \theta}{2}-\sigma_{t} \mathrm{~d} r \sin \frac{\mathrm{d} \theta}{2} \\
+\left(\tau_{\theta r}+\frac{\partial \tau_{\theta r}}{\partial \theta} \mathrm{d} \theta\right) \mathrm{d} r \cos \frac{\mathrm{d} \theta}{2}-\tau_{\theta r} \mathrm{~d} r \cos \frac{\mathrm{d} \theta}{2}+f_{r} r \mathrm{~d} \theta \mathrm{d} r=0,
\end{gathered}
$$

where $\sigma_{r}$ is the radial stress, $\sigma_{t}$ is the tangential stress, and $\tau_{r \theta}$ represents the shear stress; in this model $\tau_{\theta r}=\tau_{r \theta}=0, f_{r}$ is the physical strength.
In order to simplify the calculation process, according to the characteristics of the engineering environment, equation (1) is simplified and further equation (2) is obtained, 


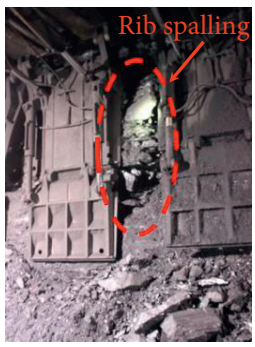

(a)

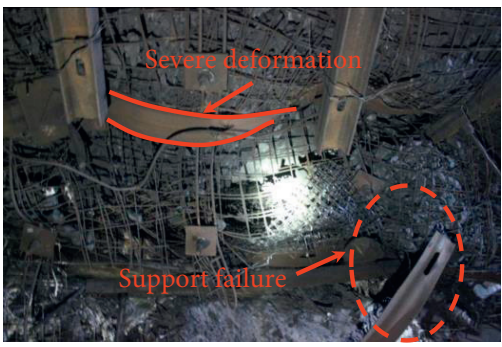

(b)

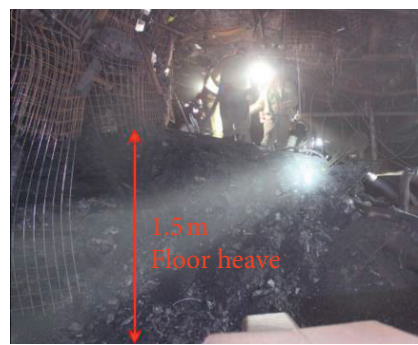

(c)

Figure 1: Damage to surrounding rock caused by high ground stress. (a) Rib spalling. (b) Roadway severe deformation. (c) Floor heave.

\begin{tabular}{|l|c|}
\hline thickness (m) & Lithology \\
\hline 3.10 & mudstone \\
\hline 4.10 & Fine sandstone \\
\hline 5.40 & Sandy mudstone \\
\hline 2.20 & Fine sandstone \\
\hline 2.70 & mudstone \\
\hline 3.25 & $\begin{array}{c}\text { Sandy mudstone } \\
\text { mudstone }\end{array}$ \\
\hline 5.40 & \begin{tabular}{c} 
mudstone \\
\hline 5.50
\end{tabular} \\
\hline
\end{tabular}

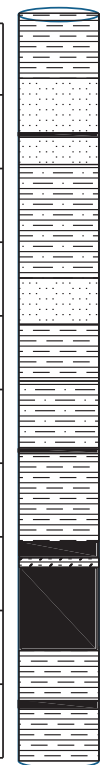

FIGURE 2: Coal seam comprehensive histogram.

$$
\left(\sigma_{r}+\mathrm{d} \sigma_{r}\right)(r+\mathrm{d} r) \mathrm{d} \theta-\sigma_{r} r \mathrm{~d} \theta-\sigma_{r} r \mathrm{~d} \theta-2 \sigma_{t} \mathrm{~d} r \sin \frac{\mathrm{d} \theta}{2}=0 .
$$

For the convenience of calculation, the equation is approximated,

$$
\sigma_{r}-\sigma_{t}+r \frac{\mathrm{d} \sigma_{r}}{\mathrm{~d} r}=0
$$

Analyze the differential volume at this point and get the geometric equation, as shown in the following equation:

$$
\begin{aligned}
& \varepsilon_{r}=\frac{(u+\mathrm{d} u)-u}{\mathrm{~d} r}=\frac{\mathrm{d} u}{\mathrm{~d} r}, \\
& \varepsilon_{t}=\frac{(r+u) \mathrm{d} \theta-r \mathrm{~d} \theta}{r \mathrm{~d} \theta}=\frac{u}{r},
\end{aligned}
$$

where $\varepsilon_{r}$ is the radial strain, $\varepsilon_{t}$ is the tangential strain, and $u$ is the radial deformation of differential volume.

According to the generalized Hooke's law, the strain expression of differential volume is obtained in the following equation,

$$
\begin{aligned}
& \varepsilon_{r}=\frac{1}{E}\left[\sigma_{r}-\mu\left(\sigma_{t}+\sigma_{z}\right)\right], \\
& \varepsilon_{t}=\frac{1}{E}\left[\sigma_{t}-\mu\left(\sigma_{r}+\sigma_{z}\right)\right],
\end{aligned}
$$

where $E$ is the elastic modulus, $\mu$ is Poisson's ratio, and $\sigma_{z}$ is the axial stress of circular hole.

Taking the derivative of equation (4), one has

$$
\frac{\mathrm{d} \varepsilon_{t}}{\mathrm{~d} r}=\frac{1}{r}\left(\varepsilon_{r}-\varepsilon_{t}\right)
$$

Substituting equation (5) into equation (6) leads to

$$
\frac{\mathrm{d} \varepsilon_{t}}{\mathrm{~d} r}=\frac{1}{r E}\left[\sigma_{r}-\sigma_{t}-\mu\left(\sigma_{t}+\sigma_{z}\right)+\mu\left(\sigma_{r}+\sigma_{z}\right)\right]=\frac{1+\mu}{r E}\left(\sigma_{r}-\sigma_{t}\right) .
$$

From equation (6),

$$
\frac{\mathrm{d} \varepsilon_{r}}{\mathrm{~d} r}=\frac{1}{E}\left(\frac{\mathrm{d} \sigma_{t}}{\mathrm{~d} r}-\mu \frac{\sigma_{r}}{\mathrm{~d} r}\right) .
$$

Combining equations (7) and (8),

$$
\frac{1+\mu}{r}\left(\sigma_{r}-\sigma_{t}\right)=\frac{\mathrm{d} \sigma_{t}}{\mathrm{~d} r}-\mu \frac{\sigma_{r}}{\mathrm{~d} r}
$$

Coordinate transformation in the rectangular coordinate system $\sigma_{r}, \sigma_{t}$ means, as shown in the following equation,

$$
\begin{aligned}
\sigma_{r} & =\sigma_{x} \cos ^{2} \theta+\sigma_{y} \sin ^{2} \theta, \\
\sigma_{t} & =\sigma_{x} \sin ^{2} \theta+\sigma_{y} \cos ^{2} \theta .
\end{aligned}
$$

According to Lame's solution, let the internal pressure $q_{1}=0$ and $q_{2}=\gamma H$ in the thick wall cylinder model.

$$
\begin{aligned}
& \sigma_{r}=\gamma H\left(1-\frac{r_{1}^{2}}{r^{2}}\right), \\
& \sigma_{t}=\gamma H\left(1+\frac{r_{1}^{2}}{r^{2}}\right) .
\end{aligned}
$$

By calculating the limit equilibrium area around the working face, the static equation is obtained as equation (3), according to the limit equilibrium condition. 


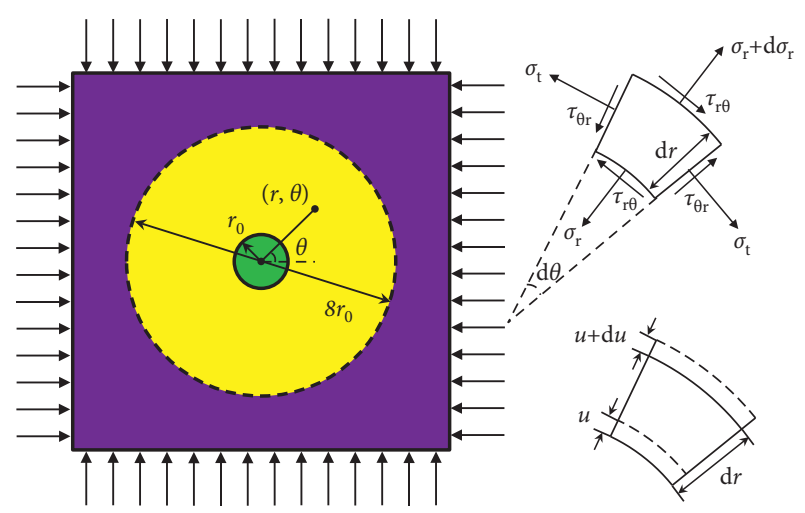

Figure 3: Simplified model of stress distribution around working face.

$$
\sigma_{t}=\frac{1+\sin \varphi}{1-\sin \varphi} \sigma_{r}+\frac{2 C \cos \varphi}{1-\sin \varphi},
$$

where $C$ is the cohesion and $\varphi$ is the internal friction angle.

Combining equations (3) and (12) and integral,

$$
\ln \left(\sigma_{r}+C \cot \varphi\right)=\frac{2 \sin \varphi}{1-\sin \varphi} \ln r+\ln A,
$$

where $A$ is the integral constant.

Substituting the boundary conditions $r=r_{1}$ and $\sigma_{r}=0$,

$$
\begin{aligned}
\sigma_{r} & =C \cot \varphi\left[\left(\frac{r}{r_{1}}\right)^{(2 \sin \varphi /(1-\sin \varphi))}-1\right], \\
\sigma_{t} & =C \cot \varphi\left[\frac{1+\sin \varphi}{1-\sin \varphi}\left(\frac{r}{r_{1}}\right)^{(2 \sin \varphi /(1-\sin \varphi))}-1\right],
\end{aligned}
$$

when the roof caving behind the working face fills the goaf, the abutment pressure value in this area gradually recovers from 0 to the original rock stress,

$$
\sigma_{t}=K \gamma H
$$

where $K$ is the stress recovery factor.

According to the comprehensive analysis for the abutment pressure at the coal seam position, from the front of the working face to the rear, it can be divided into elastic zone (a), limit equilibrium zone (b), complete pressure relief zone (c), and stress recovery zone (d), as shown in Figure 4.

\section{Numerical Analysis of Characteristics of Coal Mining Stress Distribution}

4.1. Model Establishment and Parameter Determination. Large numerical calculation models are established based on the engineering geological background of Kouzidong Mine, as shown in Figure 5. In order to study the impact of the advancing direction on the distribution of mining stress, six groups of models with the angle between the advancing direction and the minimum principal stress direction of $0^{\circ}$, $15^{\circ}, 35^{\circ}, 45^{\circ}, 60^{\circ}$, and $90^{\circ}$ were established, respectively. According to the results of on-site stress measurement, $X$ axis is determined as the minimum principal stress direction, $Y$ axis is the middle main stress direction, $Z$ axis is the maximum main stress direction, and the top of the model is the stress boundary condition, where the vertical stress load is applied to simulate the weight of overburden which is not established, and the surrounding and bottom are fixed displacement boundary conditions. The length of each model working face is $350 \mathrm{~m}$ and the width of roadway is $6 \mathrm{~m}$. In order to facilitate modeling and improve the accuracy of solution, the length, width, and height of each unit in the coal seam, roof, and floor located in the excavation range of the working face are $1 \mathrm{~m}$, and the thickness of the coal seam is $6 \mathrm{~m}$. After the working face is excavated, the excavated unit body is filled to simulate the goaf. Step by step excavation mode is adopted for the model with the same advancing direction as the actual site, which is calculated once for each excavation of $5 \mathrm{~m}$ to simulate the daily advance distance, and the goaf is filled with $20 \mathrm{~m}$ behind the coal wall.

In the process of simulation, the self-developed constitutive model is used to control the mechanical characteristics of coal and rock mass. In order to determine the model parameters, coal and rock samples are collected at 121304 working face to determine the rock mechanical parameters. According to the measured distribution characteristics of coal and rock fractures, combined with Hoek Brown criterion, the rock parameters of different layers are modified, and the rock mass parameters are obtained, as shown in Table 1. After excavation, the double yield model is used to simulate the compaction bearing characteristics of gangue in goaf. The model parameters are shown in Table 2. The parameters of the double yield model are determined by trial and error method: the model parameters are changed constantly to make the simulated stress-strain curve of gangue in goaf consistent with the prediction result of Salamon model.

4.2. Numerical Model Validation. In order to determine the reliability of the model, four borehole stress gauges were installed $200 \mathrm{~m}$ away from the front working face of the return airway, which will measure the distribution characteristics of air side leading abutment pressure of 121304 working face. The monitoring results are shown in Figure 6(a). When it is $150 \mathrm{~m}$ away from the working face, abutment pressure begins to be affected by mining, showing an upward trend, reaching a peak $10-12 \mathrm{~m}$ before the working face, and the coal body reached the limit equilibrium state; after that, the coal body entered the mining damage zone, the bearing capacity decreased, and the abutment pressure began to decrease. The coal wall near the working face is reduced to the minimum value, which is about the residual strength of the coal body. The abovementioned abutment pressure distribution characteristics indicate that the leading mining influence range of 121304 working face reaches $150 \mathrm{~m}$, and the width of the coal body damage zone in front of working face reaches $10-12 \mathrm{~m}$.

The on-site measurement and numerical calculation results are shown in Figure 6. Comparing the two results, it can be found that the trends of the two results are consistent on one side of the working face. In the length direction of the 


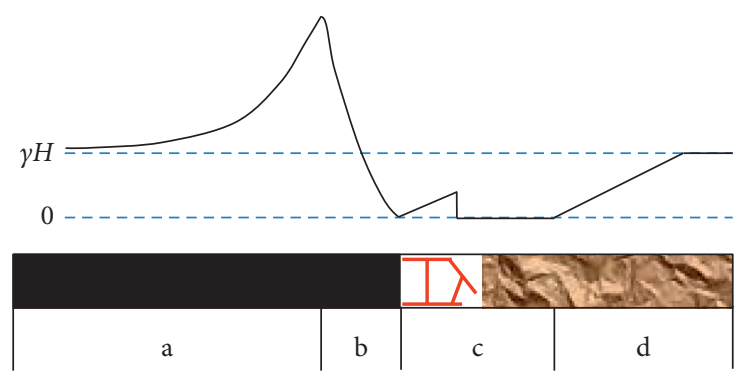

FIgURE 4: Abutment pressure distribution in advancing direction of working face.
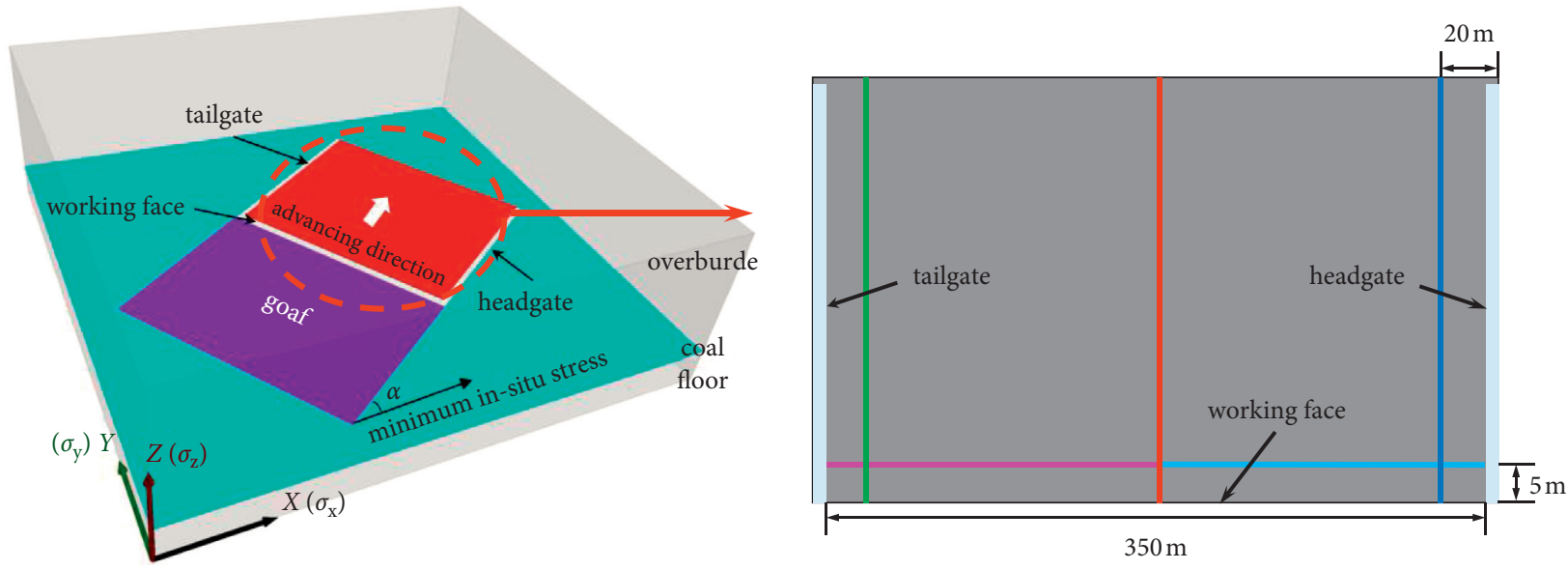

FIGURE 5: Numerical calculation model and the location of measuring line.

working face, there is a trend of first rising and then falling back from the end to the middle. Peaks appear on two sides of the working face. The measured results show that the peak value is close to $50 \mathrm{MPa}$. The numerical calculation results show that the peak position is $7 \mathrm{~m}$ away from the roadway. The abutment pressure reaches $57.8 \mathrm{MPa}$. Along the advancing direction, the change trend of the abutment pressure showed a first increase and then a decrease and finally approached the original rock stress. The peak points of numerical simulation and measured results are located $10-12 \mathrm{~m}$ in front of the working face, and the influence range was about $150 \mathrm{~m}$. It can be seen that the numerical calculation model is basically consistent with the on-site measured results, and the calculation parameters are reliable.

4.3. Analysis of Numerical Results. In order to observe the variation characteristics of mining stress under different advancing directions, two measuring lines and a plane are arranged in the coal seam $5 \mathrm{~m}$ above the coal seam floor. The measuring plane is parallel to the horizontal plane. The position of measuring line is showed in Figure 5. As shown by the red line, one measuring line is arranged in the middle of the working face along the advancing direction, and the other measuring line is arranged at $5 \mathrm{~m}$ in front of the working face along the length direction, as shown by the pink line and the light blue line.

The influence of the advancing direction on the distribution characteristics of the maximum principal stress is shown in Figure 7. Under the influence of coal seam mining, the maximum principal stress of the working face is obviously concentrated in advance of the working face, and the maximum principal stress concentration area is mainly distributed in front of the working face, and at both ends, the leading maximum principal stress presents a three-peak shape on the middle of the working face and both sides.

In the length direction of working face, the three peaks at different included angles change significantly, as shown in Figure $8(\mathrm{a})$. When the angle between the advancing direction and the minimum principal stress is $0^{\circ}$, the maximum principal stress peaks on both sides of the working face are greater than the peak in the middle of the working face, and the peaks on the left and right sides are $51 \mathrm{MPa}$. As the angle between the advancing direction of the working face and the minimum principal stress increases, the leading maximum principal stress of the working face first decreases and then increases. When the angle is equal to $45^{\circ}$, the maximum principal stress is the smallest. At this time, the peak at the middle position is $49 \mathrm{MPa}$ and the peak at both sides is $47 \mathrm{MPa}$. When the included angle increases to $90^{\circ}$, the peak at the middle position is $53 \mathrm{MPa}$, and the peak at both sides is $51 \mathrm{MPa}$. In the distribution form of the maximum principal stress of the tendency, with the increase of the included angle, the measuring line in the direction of the tendency gradually began to show an asymmetric distribution, and the peak value of the maximum principal stress in the middle part was gradually greater than the peaks at both sides. 
TABLE 1: Rock parameters.

\begin{tabular}{|c|c|c|c|c|c|c|c|c|}
\hline \multirow{2}{*}{ Lithology } & \multirow{2}{*}{$\begin{array}{l}\text { Elastic modulus } \\
\qquad(\mathrm{GPa})\end{array}$} & \multirow{2}{*}{$\begin{array}{l}\text { Poisson's } \\
\text { ratio }\end{array}$} & \multirow{2}{*}{$\begin{array}{l}\text { Cohesion } \\
(\mathrm{MPa})\end{array}$} & \multirow{2}{*}{$\begin{array}{l}\text { Internal friction angle } \\
\qquad\left(^{\circ}\right)\end{array}$} & \multirow{2}{*}{$\begin{array}{l}\text { Tensile strength } \\
(\mathrm{MPa})\end{array}$} & \multicolumn{3}{|c|}{$\begin{array}{l}\text { Softening } \\
\text { parameter }\end{array}$} \\
\hline & & & & & & $m$ & $n$ & $k$ \\
\hline Fine sandstone & 21.22 & 0.16 & 10.0 & 38 & 1.29 & 0.001 & 0.70 & 750 \\
\hline $\begin{array}{l}\text { Sandy } \\
\text { mudstone }\end{array}$ & 17.50 & 0.25 & 4.9 & 33 & 2.01 & 0.0015 & 0.65 & 400 \\
\hline Mudstone & 14.69 & 0.25 & 2.4 & 32 & 0.58 & 0.002 & 0.56 & 320 \\
\hline Coal & 2.83 & 0.20 & 1.25 & 30 & 0.15 & 0.0035 & 0.40 & 270 \\
\hline
\end{tabular}

TABLE 2: Mechanical parameters of falling gangue in goaf.

\begin{tabular}{|c|c|c|c|c|c|c|c|c|c|}
\hline \multirow{2}{*}{$\begin{array}{l}\text { Parameter } \\
\text { name }\end{array}$} & \multirow{2}{*}{$\begin{array}{l}\text { Density } \\
\left(\mathrm{kg} / \mathrm{m}^{3}\right)\end{array}$} & \multirow{2}{*}{$\begin{array}{l}\text { Bulk modulus } \\
\qquad(\mathrm{GPa})\end{array}$} & \multirow{2}{*}{$\begin{array}{l}\text { Shear modulus } \\
\qquad(\mathrm{GPa})\end{array}$} & \multirow{2}{*}{$\begin{array}{c}\text { Cohesion } \\
(\mathrm{MPa})\end{array}$} & \multirow{2}{*}{$\begin{array}{c}\text { Internal friction } \\
\text { angle }\left({ }^{\circ}\right)\end{array}$} & \multirow{2}{*}{$\begin{array}{l}\text { Tensile strength } \\
\quad(\mathrm{MPa})\end{array}$} & \multicolumn{3}{|c|}{$\begin{array}{c}\text { Blocking } \\
\text { parameters }\end{array}$} \\
\hline & & & & & & & $\begin{array}{c}a \\
(\mathrm{MPa})\end{array}$ & $\begin{array}{l}b \\
-\end{array}$ & $\begin{array}{c}c \\
(\mathrm{MPa})\end{array}$ \\
\hline Value & 2000 & 1.2 & 0.6 & 0 & 30 & 0 & 60 & 15 & 20 \\
\hline
\end{tabular}

In the advancing direction of working face, under different included angles, the maximum principal stress distribution of the working face is shown in Figure 8(b). The angle between the advancing direction and the minimum principal stress has a less impact to the maximum principal stress of the working face, and the leading influence range is about $40 \mathrm{~m}$. When the included angle is $0^{\circ}$, the maximum principal stress peak position of the working face is $6 \mathrm{~m}$ in front of the working face, and the peak point is $51.9 \mathrm{MPa}$. As the included angle increases, the peak point position moves slightly to the front of the coal wall, and the maximum principal stress peak increases slightly. When the included angle increases to $90^{\circ}$, the maximum principal stress peak position of the working face is $4 \mathrm{~m}$ before the working face, and the peak point is $52.5 \mathrm{MPa}$. In general, the angle between the advancing direction and the minimum principal stress has little effect on the distribution of the maximum principal stress.

Figure 9 shows the maximum principal stress concentration factor of the working face under different angles between the advancing direction and the minimum principal stress. The stress concentration factor is expressed in $\eta$, where $B$ is the peak stress of working face and $A$ is the in situ stress without mining disturbance. As shown in Figure 9, the maximum stress concentration factor of principal stress appears to decrease first and then increase. The minimum value of the maximum principal stress concentration factor is at the angle of $15^{\circ}$ with a value of 2.16 . As the included angle continues to increase, the stress concentration factor gradually increases. When the included angle increases to $45^{\circ}$, the increase began to slow down. When the included angle increases to $90^{\circ}$, the stress concentration factor reaches the maximum value of 2.25 .

In summary, the angle between the minimum principal stress and the advancing direction of the working face has a greater influence on the mining stress distribution in working face. In terms of stress, with the increase of the angle, the mining stress as a whole shows a trend of decreasing first and then increasing. In terms of morphological distribution, the spatial division characteristics of mining stress are also affected by the included angle. With the increase of the included angle, the peak values of the double peaks on both sides are gradually smaller than the peaks in the middle.

Under the condition of different included angles between the direction of the initial minimum ground stress $(X-$ axis) and the advancing direction of the working face, the evolution characteristics of the maximum principal stress rotation trajectory are shown in Figure 10. The red, green, and blue measuring lines are arranged along the advancing direction of the working face. The red measuring line is arranged in the middle of the working face, and the green and blue measuring lines are arranged $20 \mathrm{~m}$ away from the roadway at both ends. The pink and light blue measuring lines are arranged from both ends of the tailgate and headgate to the middle of working face along the length direction of the working face, $5 \mathrm{~m}$ ahead of the working face. The maximum principal stress rotation trajectory on the advancing direction measuring line always deflects in the direction of the goaf in the vertical plane parallel to the advancing direction of the working surface. Therefore, the angle between the 90-270 axis direction and the maximum principal stress rotation trajectory on the strike measuring line gradually increases. It always maintains the angle between the advancing direction of the working face and the initial minimum ground stress direction. The maximum principal stress rotation trajectory on the length direction measuring line always maintains the arc of the symmetry axis with the advancing measuring line, roughly toward the roadway on both sides of the working face direction. In summary, the size of the rotation angle of the maximum principal stress is less affected by the direction of propulsion, but the direction of rotation is obviously affected by the advancing direction. 


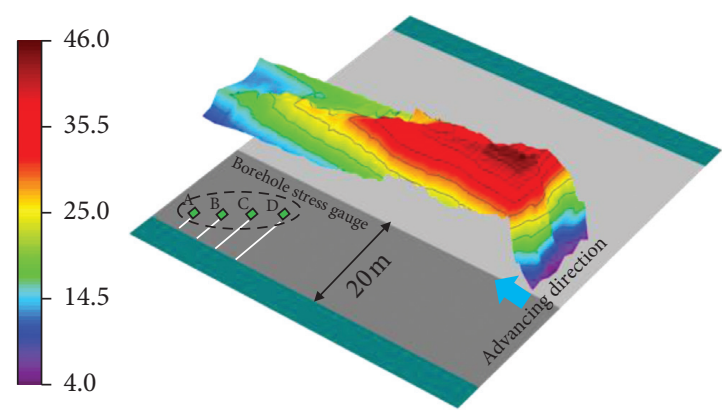

(a)

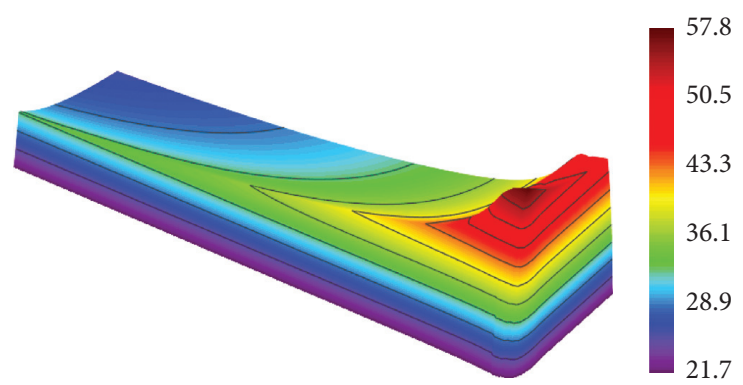

(b)

Figure 6: Comparison of on-site measurement results and numerical calculation results. (a) On-site measurement. (b) Numeral calculations.

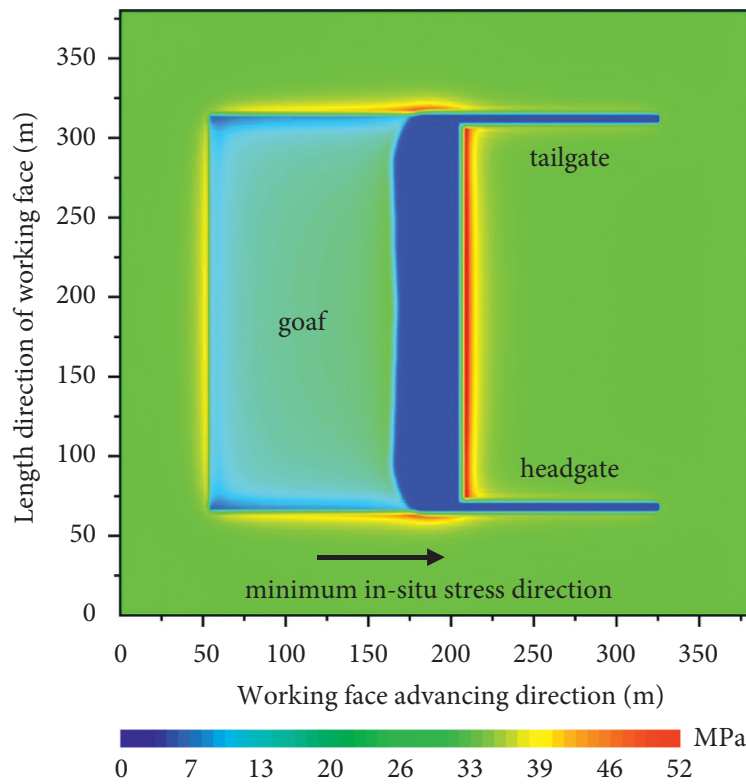

(a)
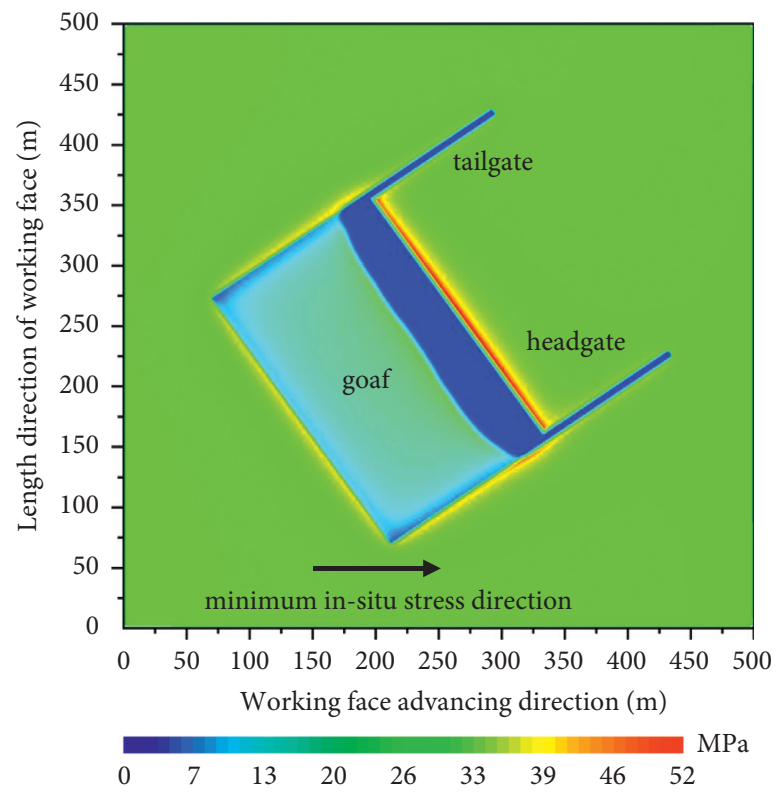

(c)
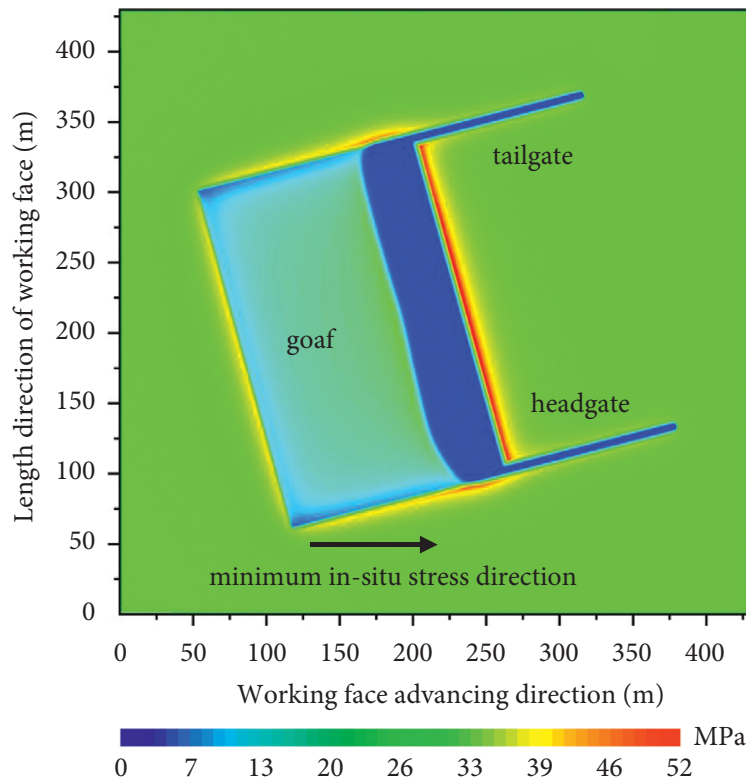

(b)

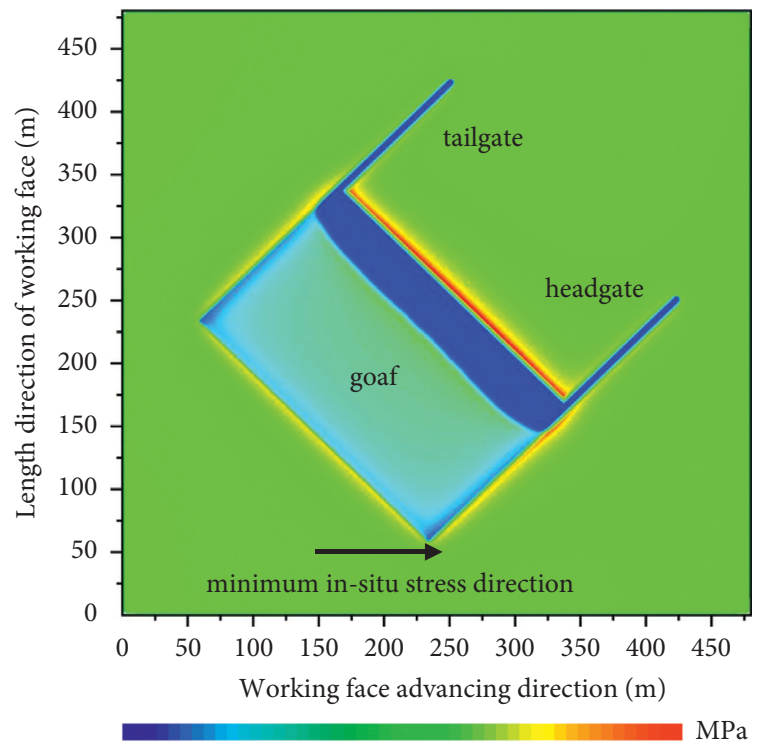

(d)

Figure 7: Continued. 

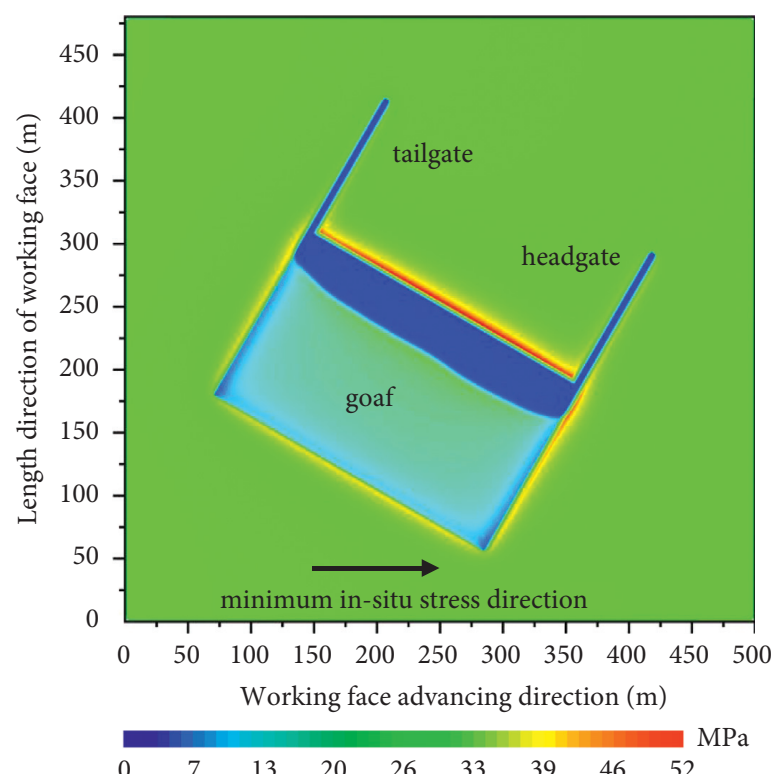

(e)
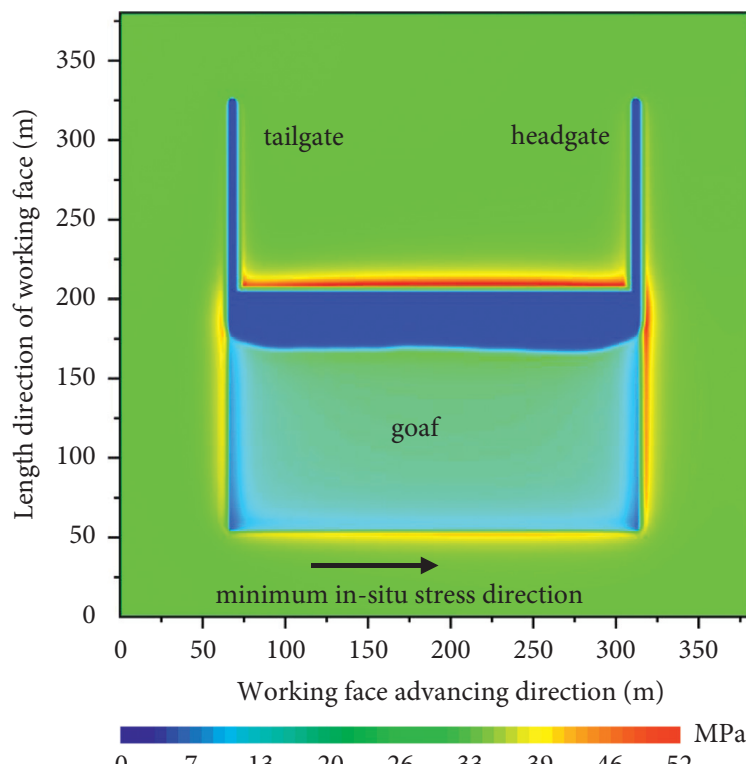

(f)

FiguRE 7: Influence of advancing direction on maximum principal stress distribution of working face. (a) $0^{\circ}$. (b) $15^{\circ}$. (c) $30^{\circ}$. (d) $45^{\circ}$. (e) $60^{\circ}$. (f) $90^{\circ}$.

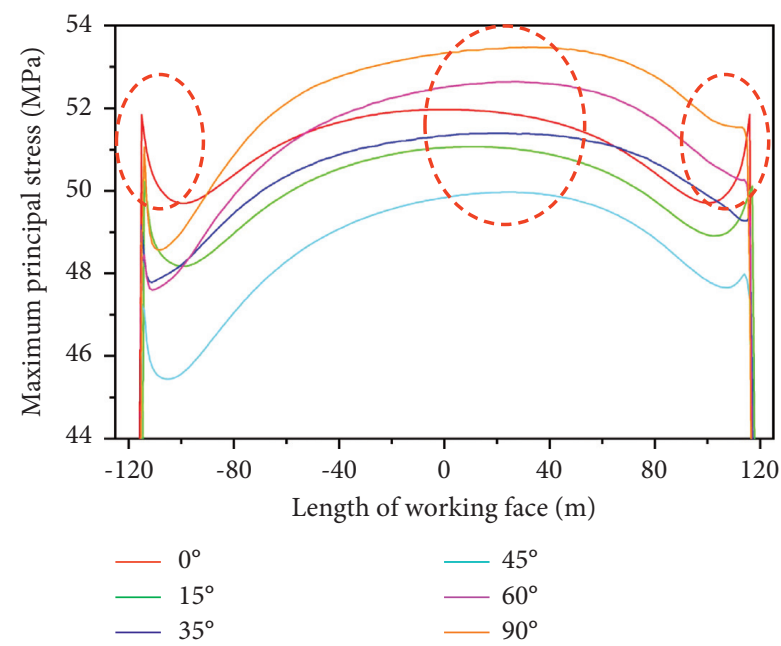

(a)

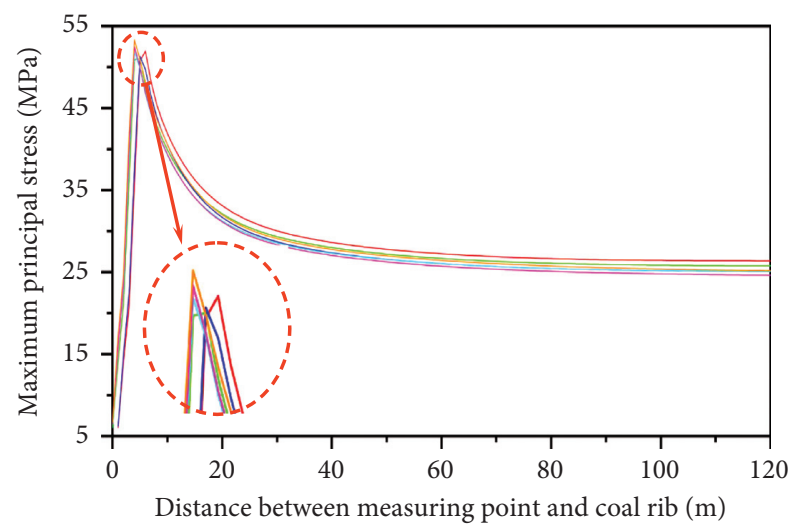

$\begin{array}{ll}-0^{\circ} & -45^{\circ} \\ -15^{\circ} & -60^{\circ} \\ -35^{\circ} & -90^{\circ}\end{array}$

(b)

FIGURE 8: Maximum principal stress distribution of working face under different advancing direction and minimum principal stress angle. (a) The direction of length. (b) The direction of advancing.

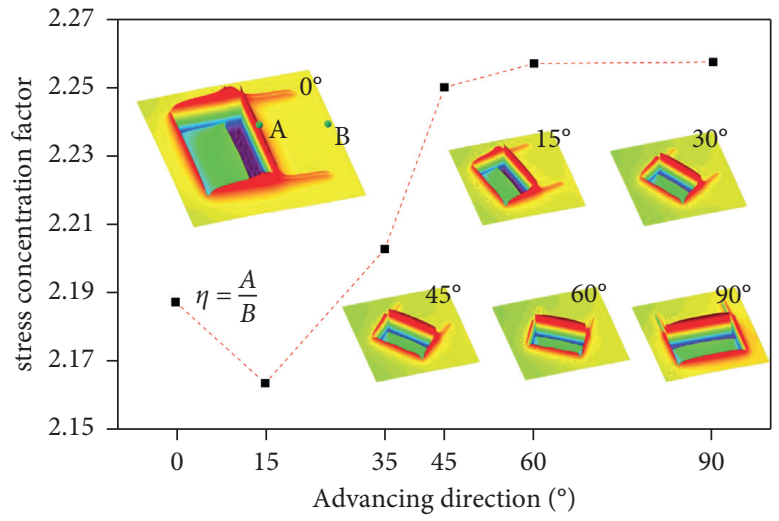

FIGURE 9: Maximum principal stress concentration factor of working face in different advancing directions. 

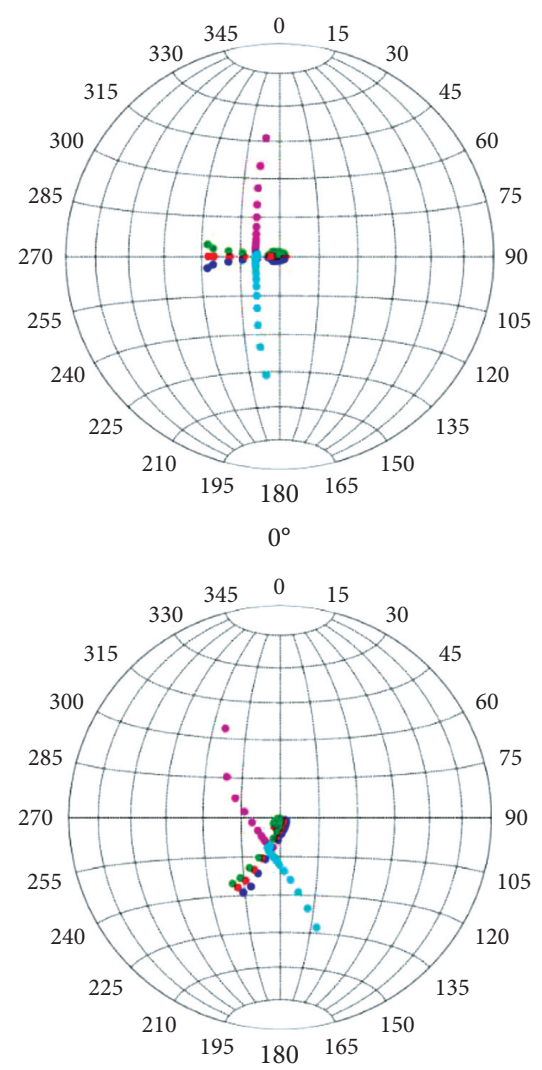

$45^{\circ}$
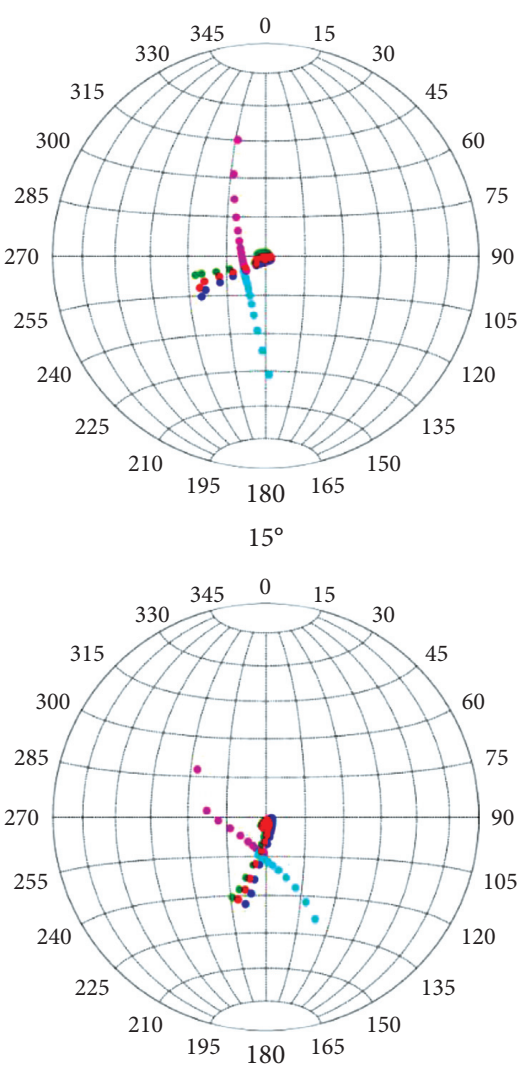

$60^{\circ}$
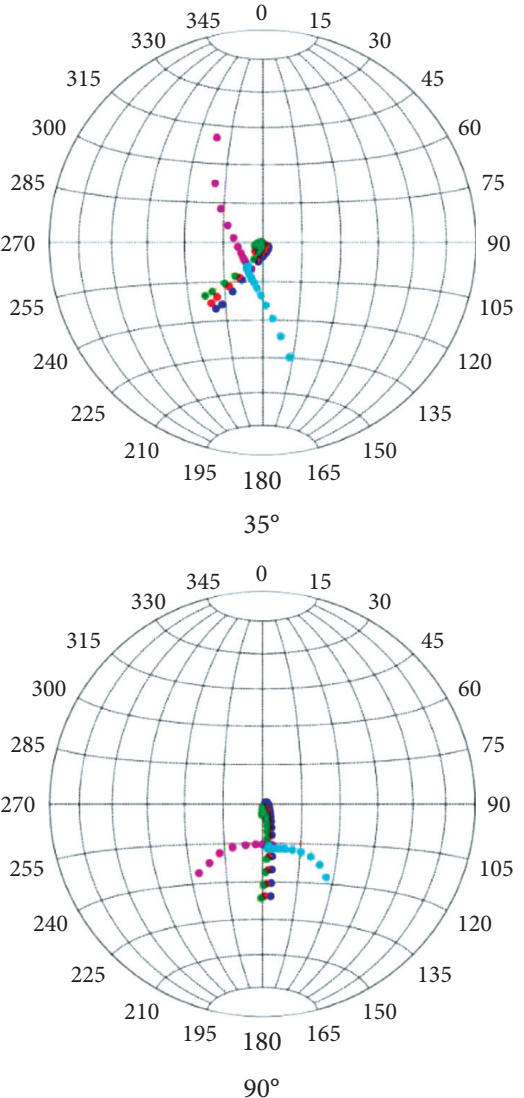

$90^{\circ}$

FIGURE 10: Rotation trajectory characteristics of maximum principal stress under different advancing directions.

\section{Conclusions}

(1) The on-site measurement has obtained the in situ stress distribution of the deep part of the Kouzidong Mine. The maximum principal stress direction is the vertical direction with a magnitude of $25.12 \mathrm{MPa}$. The direction of the minimum principal stress is east by north $55^{\circ}$ of the horizontal direction, and the magnitude is $12.89 \mathrm{MPa}$. The deep mine of Kouzidong Mine has an advanced mining influence range of $150 \mathrm{~m}$, and the maximum stress concentration position is about $10 \mathrm{~m}$ in front of the coal wall. The results of numerical simulation agree well with this feature.

(2) Under the influence of coal seam mining, the maximum principal stress of the working face is obviously concentrated in advance of the working face, and the maximum principal stress concentration area is mainly distributed in front of the working face, and at both ends, the leading maximum principal stress presents a three-peak shape on both sides of the working face and the middle of the working face.

(3) Through the establishment of numerical models of different advancing directions, it is found that the stress concentration is located at $7-10 \mathrm{~m}$ in front of the working face, and in the length direction of the working face, the distribution characteristics of three-peak stress are all presented. With the increase of the angle between the advancing direction and the minimum principal stress, the mining stress concentration first decreases and then increases and tends to be stable. Therefore, in the safe and efficient production of super-long working face in deep mine, it is necessary to consider the influence between the advancing direction and the minimum principal stress angle, so as to minimize the stress concentration of the working face and strengthen the support at the end and the middle of the working face to prevent the occurrence of rib spalling and other accidents.

\section{Data Availability}

The data used to support the findings of this study are included within the article.

\section{Conflicts of Interest}

The authors declare that they have no conflicts of interest.

\section{Acknowledgments}

This work was financially supported by the National Natural Science Foundation of China (51934008), which is gratefully acknowledged. 


\section{References}

[1] H. P. Xie, "Research review of the state key research development program of China: deep rock mechanics and mining theory," Journal of China Coal Society, vol. 44, no. 5, pp. 1283-1305, 2019.

[2] J. C. Wang, "Sustainable coal mining based on mining ground control," Journal of Mining and Strata Control Engineering, vol. 1, no. 2, pp. 40-47, 2019.

[3] Q. Wang, B. Jiang, R. Pan et al., "Failure mechanism of surrounding rock with high stress and confined concrete support system," International Journal of Rock Mechanics and Mining Sciences, vol. 102, pp. 89-100, 2018.

[4] J. Xie, J. Xu, and F. Wang, "Mining-induced stress distribution of the working face in a kilometer-deep coal mine-a case study in Tangshan coal mine," Journal of Geophysics and Engineering, vol. 15, no. 5, pp. 2060-2070, 2018.

[5] W. Pytel, J. Świtoń, and A. Wójcik, "The effect of mining face's direction on the observed seismic activity," International Journal of Coal Science \& Technology, vol. 3, no. 3, pp. 322329, 2016.

[6] K. Yang, X. He, L. Dou, W. Liu, L. Sun, and H. Ye, "Experimental investigation into stress-relief characteristics with upward large height and upward mining under hard thick roof," International Journal of Coal Science \& Technology, vol. 2, no. 1, pp. 91-96, 2015.

[7] D. Z. Kong, S. J. Pu, Z. H. Cheng et al., "Coordinated deformation mechanism of the top coal and filling body of gobside entry retaining in a fully mechanized caving face," International Journal of Geomechanics, vol. 21, no. 4, 2021.

[8] D.-Z. Kong, Z.-B. Cheng, and S.-S. Zheng, "Study on the failure mechanism and stability control measures in a largecutting-height coal mining face with a deep-buried seam," Bulletin of Engineering Geology and the Environment, vol. 78, no. 8, pp. 6143-6157, 2019.

[9] S. Li, M. Gao, X. Yang et al., "Numerical simulation of spatial distributions of mining-induced stress and fracture fields for three coal mining layouts," Journal of Rock Mechanics and Geotechnical Engineering, vol. 10, no. 5, pp. 907-913, 2018.

[10] J. M. Zhang, Q. S. Li, Y. Zhang et al., "Definition of deep coal mining and analysis of mining response," Journal of China Coal Society, vol. 44, no. 5, pp. 1314-1325, 2019.

[11] H. P. Xie, Z. T. Zhang, F. Gao et al., "Stress-fracture-seepage field behavior of coal under different mining lay-outs," Journal of China Coal Society, vol. 41, no. 10, pp. 2405-2417, 2016.

[12] J. C. Wang, Z. H. Wang, J. Yang et al., "Mining-induced stress rotation and its application in longwall face with large length in kilometer deep coal mine," Journal of China Coal Society, vol. 45, no. 3, pp. 876-888, 2020.

[13] H. P. Xie, H. W. Zhou, D. J. Xue et al., "Research and thinking on deep coal mining and extreme mining depth," Journal of China Coal Society, vol. 37, no. 4, pp. 535-542, 2012.

[14] M. C. He, H. P. Xie, S. P. Peng et al., "Research on rock mechanics in deep mining," Chinese Journal of Rock Mechanics and Engineering, vol. 24, no. 16, pp. 2803-2813, 2005.

[15] Y. F. Han, Z. H. Wang, and Y. S. Tang, "Principal stress rotation in longwall top-coal caving face adjacent to the gob," Journal of China Coal Society, vol. 45, no. S1, pp. 12-22, 2020.

[16] J. C. Wang and Z. H. Wang, "Propagating mechanism of topcoal fracture in longwall top-coal caving mining," Journal of China Coal Society, vol. 43, no. 9, pp. 2376-2388, 2018.

[17] J. Wang, W. Wei, and J. Zhang, "Theoretical description of drawing body shape in an inclined seam with longwall top coal caving mining," International Journal of Coal Science \& Technology, vol. 7, no. 1, pp. 182-195, 2020.

[18] H. P. Kang, G. F. Wang, P. F. Jiang et al., "Conception for strata control and intelligent mining technology in deep coal mines with depth more than $1000 \mathrm{~m}$," Journal of China Coal Society, vol. 43, no. 7, pp. 1789-1800, 2018.

[19] J. C. Wang, S. L. Yang, W. J. Wei et al., "Drawing mechanisms for top coal in longwall top coal caving (LTCC): a review of two decades of literature," International Journal of Coal Science \& Technology, 2021.

[20] J. F Lou, F. Q. Gao, J. H. Yang et al., "Characteristics of evolution of mining-induced stress field in the longwall panel: insights from physical modeling," Int. J. Coal Sci. Technol., 2021.

[21] A. E. Radwan, W. K. Abdelghany, and M. A. Elkhawaga, "Present-day in-situ stresses in Southern Gulf of Suez, Egypt: insights for stress rotation in an extensional rift basin," Journal of Structural Geology, vol. 147, Article ID 104334, 2021.

[22] A. Saeidi, S. heidarzadeh, S. Lalancette et al., "The effects of in situ stress uncertainties on the assessment of open stope stability: case study at the Niobec Mine, Quebec (Canada)," Geomechanics for Energy and the Environment, vol. 25, Article ID 100194, 2021.

[23] H. J. Guo, M. Ji, and W. S. Zhao, "Analysis of the distribution characteristics and laws of in situ stress in China's coal mines," Arabian Journal of Geosciences, vol. 13, 2020.

[24] Q. Y. Zhang, F. Li, D. Kang et al., "Experimental investigation on splitting failure of high sidewall cavern under three-dimensional high in-situ stress," Tunnelling and Underground Space Technology, vol. 108, 2021.

[25] J.-c. Yang, K.-w. Liu, X.-d. Li, and Z.-x. Liu, "Stress initialization methods for dynamic numerical simulation of rock mass with high in-situ stress," Journal of Central South University, vol. 27, no. 10, pp. 3149-3162, 2020.

[26] Z. C. Qin, B. Cao, Y. L. Liu et al., "Study on in Situ Stress Measurement and Surrounding Rock Control Technology in Deep Mine," Geofluids, vol. 2020, Article ID 8839333, 12 pages, 2020.

[27] L. H. Li, J. C. Wang, S. L. Yang et al., "Smart control methodology for light sources based on halogen lamp - a solution for eco- and user- friendly lighting in underground mining," Optik, vol. 242, Article ID 167085, 2021.

[28] J. G. Wang, B. Hu, H. Liu, Y. Han, and J. Liu, "Effects of "softhard" compaction and multiscale flow on the shale gas production from a multistage hydraulic fractured horizontal well," Journal of Petroleum Science and Engineering, vol. 170, pp. 873-887, 2018.

[29] D. Li, Z. Sun, T. Xie, X. Li, and P. G. Ranjith, "Energy evolution characteristics of hard rock during triaxial failure with different loading and unloading paths," Engineering Geology, vol. 228, pp. 270-281, 2017.

[30] X. M. Song, T. F. Gu, and Z. H. Yan, "Research on the influence of the increase in the length of the large mining face in shallow buried seams on the appearance of ground pressure," Chinese Journal of Rock Mechanics and Engineering, vol. 26, 2007.

[31] X. B. Li, F. Q. Gong, S. F. Wang et al., "Dynamic and static combined loading mechanism and dynamic criterion of rockburst in deep hard rock mines," Journal of Rock Mechanics and Engineering, vol. 38, 2019.

[32] G. Z. Yin, X. Li, J. Lu et al., "Research on the disaster mechanism of composite dynamic disasters under dynamic 
and static loads in deep mining," Journal of China Coal Society, vol. 42, 2017.

[33] W. Yang, B.-q. Lin, and J.-t. Xu, "Gas outburst affected by original rock stress direction," Natural Hazards, vol. 72, no. 2, pp. 1063-1074, 2014.

[34] V. I. Karev, D. M. Klimov, Y. F. Kovalenko, and K. B. Ustinov, "Fracture model of anisotropic rocks under complex loading," Physical Mesomechanics, vol. 21, no. 3, pp. 216-222, 2018.

[35] S. V. Kuznetsov and V. A. Trofimov, "Original stress state of coal seams," Journal of Mining Science, vol. 39, no. 2, pp. 107-111, 2003.

[36] A. H. Deliormanli and N. H. Maerz, "Stress related fracturing in dimension stone quarries," IOP Conference Series: Earth and Environmental Science, vol. 44, no. 5, 2016. 